\title{
Descrição de Ruellia brevifolia (Pohl.) C. Ezcurra (Acanthaceae) em vege- tação ripária no sudoeste de Goiás, Brasil
}

\author{
Antonio Carlos Pereira de Menezes Filho ${ }^{\mathrm{a}^{*}}$ \\ a Instituto Federal de Educação, Ciência e Tecnologia Goiano, Campus Rio Verde, Goiás, Brasil \\ *Autor correspondente (astronomoamadorgoias@gmail.com)
}

\section{N F O}

\section{Keyworks}

genus Ruellia

phenological characteristics

Cerrado dominan

phytophysiognomy

\section{Palavras-chaves}

gênero Ruellia

características fenológicas

domínio Cerrado

fitofisionomia

\begin{abstract}
A B S T R A C T
Description of Ruellia brevifolia (Pohl.) C. Ezcurra (Acanthaceae) in riparian vegetation in southwest Goiás, Brazil

Ruellia brevifolia is a plant species belonging to the Acanthaceae family found in the Cerrado domain. The study aimed to describe the species $R$. brevifolia in an area of Riparian vegetation, phytophysiognomic formation of the Cerrado located in the Southwest of Goiás, Brazil. The study was carried out in a reserve of permanent preservation area (PPA) located in the municipality of Rio Verde, Goiás, Brazil. The study area was defined as Riparian vegetation, a soil rich in dolomitic limestone, the population of $R$. brevifolia was evaluated for plant height (300 individuals) using tape measure, population set and the flowering period. The study was carried out between August 2019 and February 2020 showing a discontinuous pattern, without alternating between Chasmogamous $(\mathrm{CH})$ and Eleistogamous (CL) or intermediate forms after this period only fruiting plants were described. Population groups with 5 to 67 $\mathrm{m}^{2}$ have been described, presenting a dense and discontinuous area, plant height between 30.5 to $92.8 \mathrm{~cm}$ in height. This was the first report of Ruellia brevifolia in an area of Riparian vegetation in the Cerrado and the first brief description of the species in Southwest Goiás, Brazil. Further studies should be carried out in this area of Riparian vegetation, evaluating which birds and/or insects pollinate R. brevifolia, as well as other phenological and phytochemical characteristics.
\end{abstract}

\section{R E S U M O}

Ruellia brevifolia é uma espécie vegetal pertencente a família Acanthaceae encontrada no domínio Cerrado. $\mathrm{O}$ estudo teve por objetivo descrever a espécie $R$. brevifolia em uma área de vegetação Ripária, formação fitofisionômica de Cerrado localizado no Sudoeste de Goiás, Brasil. O estudo foi realizado em uma reserva de área de preservação permanente (APP) localizada no município de Rio Verde, Goiás, Brasil. A área de estudo foi delimitada como de formação vegetal Ripária, solo rico em calcário dolomítico, a população de $R$. brevifolia foi avaliada quanto a altura de plantas (300 indivíduos) utilizando fita métrica, conjunto populacional e o período de floração. O estudo foi realizado entre os meses agosto de 2019 a fevereiro de 2020, apresentando padrão descontínuo, sem alternância entre Clasmógamas (CA) e Cleistógamas (CL) ou formas intermediárias, após esse período, apenas plantas em frutificação foram descritas. Grupamentos populacionais com 5 a $67 \mathrm{~m}^{2}$ foram descritos, apresentando densa e descontínua área, altura de plantas entre 30,5 a $92,8 \mathrm{~cm}$ de altura. Este foi o primeiro relato de Ruellia brevifolia em área de vegetação Ripária no Cerrado e a primeira descrição breve da espécie no Sudoeste de Goiás, Brasil. Novos estudos deverão ser realizados neste área de vegetação Ripária, avaliando quais são as aves e/ou insetos polinizadores de $R$. brevifolia, bem como, outras características fenológicas e fotoquímicas. 


\section{INTRODUÇÃO}

O domínio Cerrado é o segundo maior em área de vegetação natural, estando atrás apenas do bioma Amazônico brasileiro. Este domínio apresenta em média 12.000 espécies pertencentes a flora de plantas vasculares (Mendonça et al., 2008; Batalha, 2011). Devido esse imensurável banco genético vegetal, o Cerrado é considerado um hotspots com rico número de espécies vegetais e de animais no mundo (Mittermeie et al., 2005). São inúmeras formações vegetais dentro deste ambiente, que se misturam entre cidades e áreas agrícolas, que a cada ano vem perdendo grandes áreas naturais de vegetação devido a queimadas criminosas, a abertura de pastagens para criação de gado e a novas áreas de lavouras nas culturas de cana-de-açúcar, soja, sorgo e milho (Sano et al., 2007; Ferreira et al., 2017). É nesse ambiente de rica pluraridade fitofisionômica que pode-se encontrar uma grande variedade de famílias que estão inseridas no Reino Vegetal, como a família Acanthaceae (Araújo et al., 2014; VillanuevaEspinoza e Condo, 2019).

A família Acanthaceae é composta por cerca de 250 gêneros e mais de 4.000 espécies (Wasshausen, 1995; Braz et al., 2002; Lima e Gandolfi, 2009; Azevedo e Braz, 2018). Sendo o gênero Ruellia atualmente o maior e mais diversificado gênero de Acanthaceae, apresentando em média 300 espécies distribuídas em diferentes tipos de formação vegetal nas regiões tropicais e subtropicais. Nas Américas o principal centro de diversidade, está localizado no Brasil, com o maior número, com 40 gêneros e 542 espécies (Braz et al., 2002; Miranda e Vieira, 2016; Azevedo e Braz, 2018).

De acordo com Daniel (1992), Hendrén et al. (1995) e Braz et al. (2002), as relações entre os táxons infrafamiliares ainda não apresentam bem resolvidas, os inúmeros estudos florísticos preferiram manter as Acanthaceae em sentido amplo, com a inclusão do gênero Mendoncia que foi incluído a esta família. No entanto, o uso de técnicas de DNA verificando a família Acanthaceae, por enquanto descrevem como um grupo monofilético com grupos irmãos de subfamílias, sendo as principais Thunbergioideae, Mendoncia e Nelsonioideae (Scotland et al., 1995; Hedrén et al., 1995; McDade e Moody, 1999; McDade et al., 2000; Schwarzbach e McDade, 2002).

A espécie Ruellia brevifolia é conhecida popularmente por "pingo-de-sangue ou jujumiudo" descrita como sendo amplamente distribuída na América do Sul, desde a Colômbia até o Norte da Argentina com estudos para o Brasil com distribuição relatados para os estados de Minas Gerais, São Paulo, Santa Caratina e Goiás. Esta espécie é descrita como típica cleistogâmica, mecanismo de reprodução sendo observado em outras 15 espécies do gênero Ruellia (Wasshausen e Smith, 1969; MacDade, 1985; Kameyama, 1991; Kress e Beach, 1994; Kameyama, 1995; Braz et al., 2002; Lima et al., 2005; Lima e Vieira, 2006).

$R$. brevifolia apresenta hábito ornitófilo, sendo este, observado em várias outras espécies de Acanthaceae, onde inúmeras espécies de beijaflores e em menor quantidade de algumas espécies de insetos como leptodópteros sendo os principais polinizadores. $R$. brevifolia apresenta porte do tipo herbáceo ou subarbustivo, com até $1 \mathrm{~m}$ de altura, ramos levemente quadrangulares, glabrescentes; caule ligeiramente anguloso e ereto; suas folhas são opostas, pecioladas e ovadas $8,5-15,9 \times 4,6-9,9 \mathrm{~cm}$, ápice acuminado, base cuneada, margem íntegra a levemente crenada, ciliada, subconcolor, glabra ou com pilosidade esparsa, principalmente nas nervuras, nervuras secundárias 6-8 pares; pecíolo 1,5-3,5 cm de comprimento; com inflorescências axilares ou cimas multifloras ou dicásios compostos, laxos, longo-pedunculados; brácteas e bactéolas foliáceas, flores abertas, potencialmente cruzadas de coloração vermelha, e fechadas, obrigatoriamente autopolinizadas e frutos com sementes 6-8, suborbiculares (Braz et al., 2002; Lima e Vieira, 2006). De acordo com Ezcurra (1989) e Ezcurra e Azuke (1989), R. brevifolia é utilizada como planta ornamental devido as belas flores.

Embora existam estudos fragmentados sobre $R$. brevifolia no Brasil como descrito anteriormente, ainda pouco se conhece sobre sua fenologia e seus habitats dentro dos biomas e domínio Cerrado, sendo essas caractrísticas de importância pontual para completa descrição de uma espécie vegetal, como altura de planta, número populacional, período de floração, produção de frutos, quimiotipos e tolerância a áreas de ambiente natural, tipos de solos e umidade relativa.

$\mathrm{O}$ trabalho teve por objetivo informar $\mathrm{e}$ descrever a presença e as características fenológicas de Ruellia brevifolia em uma área de vegetação do tipo Ripária próximo a curso d'água no Sudoeste do estado de Goiás, Brasil.

\section{MATERIAL E MÉTODOS}

A área de estudo apresenta fitofisionomia tipo Mata Ripária, formando um complexo de preservação permanente (APP) pertencente a um hotel fazenda, com a seguinte coordenada geográfica $\left(18^{\circ} 03\right.$ '33.6' $\left.\mathrm{S} \quad 50^{\circ} 52^{\prime} 56.0^{\prime \prime} \mathrm{W}\right)$, na região Sudoeste, município de Rio Verde, Goiás, Brasil. Inicialmente, foi realizado a primeira excursão a área para conhecimento do local no mês 
de Julho de 2019. E em seguida, foi realizada excursões entre os meses de Agosto de 2019 a Abril de 2020 na área de coleta onde $R$. brevifolia foi observada. Amostras frescas de R. brevifolia foram coletadas para identificação somente no mês de Novembro de 2019, período em que a população foi observada com início de florescimento. A área de vegetação foi determinada como do tipo Ripária seguida de margem de curso d'água (rio Cabeleira).

O clima da região é caracterizado por uma estação seca fria/quente, entre abril a setembro (temperatura média $\sim 27^{\circ} \mathrm{C}$ ), uma estação úmida e quente entre outubro a março (temperatura média $\sim 29^{\circ} \mathrm{C}$ ).

A espécie foi identificada pelo Biólogo $\mathrm{MSc}^{\circ}$. Antonio Carlos Pereira de Menezes Filho, e sem seguida, uma exsicata foi herborizada e depositada no Herbário do Instituto Federal Goiano, laboratório de Sistemática Vegetal com o seguinte Voucher: HRV 2.077. A descrição da área e do vegetal foi realizada conforme as condições do ambiente de coleta. A seguir, estão apresentadas as chaves de identificação de Acanthaceae e gênero/espécie de Ruellia conforme descrito por Braz et al. (2002) modificado para este estudo. A espécie $R$. brevifolia (Pohl) C. Ezcurra na classificação infragenérica Ezcurra (1993) grupo Physiruellia e por Tripp (2007) clado Physiruellia.

\section{Chave de identificação da família Acanthaceae}

1. Plantas trepadeiras; cálice reduzido, inteiro ou com segmentos inconspícuos; fruto drupáceo ... 3. Mendoncia

1'. Plantas herbáceas, subarbustivas ou arbustivas; cálice com segmentos desenvolvidos; fruto cápsula.

2. Flores reunidas em espigas terminais simples; corola 2-labiada; estames 2 ................................. 2. Justicia

2'. Flores solitárias ou reunidas em fascículos, cimas, dicásios ou panícula de espigas, terminais e/ou axilares; corola tubulosa ou infundibuliforme; estames 4.

3. Inflorescência em espigas ou panículas de espigas, às vezes, corimbiformes, terminais e axilares; anteras 1-tecas; sementes 4

3'. Inflorescência em cimas, dicásios ou fascículos, axilares; anteras 2-tecas; sementes 5-14

\section{Ruellia}

\section{Chave de indentificação das espécies do gênero Ruellia}

1. Folhas ovadas, pecíolo 1,5-3,5 cm compr.; corola tubulosa, vermelha 4.1. $R$. brevifolia

1'. Folhas estreitamente elípticas ou oblongas, pecíolo 0,2-1 cm compr.; corola infundibuliforme, branca, lilás, rósea ou fúcsia

2. Flores reunidas em fascículos, corola branca a lilás, às vezes com mancha vinácea na fauce, 2-2,8 $\mathrm{cm}$ compr.; cápsula clavada, porção basal sólida desenvolvida 4.2. R. menthoides

2'. Flores reunidas em cimas monocasiais, corola rósea ou fúcsia, $4-5,5 \mathrm{~cm}$ compr.; cápsula obovada, porção basal sólida reduzida 4.3. R. subsessilis

A altura foi determinada em 300 indivíduos, sendo utilizado fita métrica $(3 \mathrm{~m})$. A análise estatística sobre as plantas foi expressa a partir da média aritmética da soma da área amostral determinada, seguida de \pm desvio padrão. Foi utilizado o programa estatístico PAST 3 (versão livre, 2020).

\section{RESULTADOS E DISCUSSÃO}

A população de $R$. brevifolia foi observada habitando somente na área de estudo com fitofisionomia específica de Mata Ripária, próximo ao curso d'água onde estão localizados grupamentos de cachoeiras. Além dessa fitofisionomia, ocorre também em área mais elevada, outras duas fitofisionomias de Cerrado sentido restrito e Cerradão, no entanto, buscas realizadas durante o período desse estudo não foi observado indivíduos de $R$. brevifolia, restringindo essa espécie a locais com maior sombreamento e oferta hídrica. Os agrupamentos de $R$. brevifolia apresentaram-se densos e descontínuos com áreas com variação entre 5 a $67 \mathrm{~m}^{2}$. Resultados similares foram registrados por Sigrist e Sazima (2002) onde observaram em uma área de estudo localizada no estado de São Paulo, Brasil, grupamentos densos e descontínuos ocupando áreas entre 10 a $80 \mathrm{~m}^{2} . R$. brevifolia foi acompanhada apresentando no mês de Novembro 2019, início do período de floração que se estendeu até fevereiro de 2020, esse período coincide com a estação chuvosa para a região Sudoeste de Goiás, Brasil. Após esse período, foram observadas plantas apenas com frutos, sugerindo que possivelmente que a espécie possa apresentar tipo de semente recalcitrante.

O padrão fenológico apresentado no grupo de $R$. brevifolia avaliado nesse estudo, não apresenta similaridade com o padrão descrito nos estudos de Newstrom et al. (1994) e Sigrist e Sazima (2002), onde os pesquisadores discutem que essa espécie é do tipo contínuo, apesar dos indivíduos de $R$. brevifolia também apresentarem padrão subanual, onde nos períodos entre os picos de floração há 
pouca ou nenhuma flor observada nesses estudos.

O tipo de floração de $R$. brevifolia avaliadas na área desse estudo, não mantêm alternância de flores casmógamas (CA) e cleistógamas (CL), e/ou formas intermediárias entre esses dois tipos florais, ou seja, flores CA reduzidas e semicleistógamas (Long, 1971; 1974), portanto, não há formação de sementes durante todo o ano, discordando dos estudos de Pedrotti e Guarin Neto (1998) e Sigrist e Sazima (2002), onde os pesquisadores dizem que é vantajoso para esta espécie que ocupa áreas relativamente abertas e sujeitas a diversos tipos de alterações, incluindo também impacto antrópico.

No estudo realizado em 2005 por Lima e colaboradores, os pesquiadores observaram em $R$. brevifolia grupamentos na Reserva Florestal Mata do Paraíso, município de Viçosa, estado de Minas Gerais, Brasil, onde em flores CA foram observadas floração praticamente por todo o ano, exceto entre os meses de Agosto a Setembro, assim como flores CL, exceto entre os meses de Janeiro a Fevereiro, havendo extensa sobreposição na produção desses dois tipos florais. A maior produção de flores CL foi observada nos meses de Maio a Setembro, ou seja, principalmente durante a estação seca. De modo geral, um indivíduo produz, primeiramente, flores do tipo CA, e em seguida, flores do tipo CA e CL e, posteriormente, apenas flores do tipo CL. A produção de flores CL em $R$. brevifolia, principalmente no período seco, incluindo os meses de Julho a Agosto, e sua ausência ou baixa ocorrência durante quase todo período úmido, sugerem que as condições ambientais podem estar influenciando a produção desse tipo floral (Sigrist e Sazima, 2002; Lima et al., 2005; Demetrio et al., 2016). Estudos quanto ao período sazonal de chuvas, tipos de vegetação, proximidades a cursos d'água e tipo fisiológico da semente de $R$. brevifolia devem ser investigados, para que se possa haver ligação entre a fenologia floral, a ocorrência de maior ou menor quantidade de sementes e sua fisiologia reprodutiva em diferentes ambientes naturais ou com antropização.

De acordo com Sigrist e Sazima (2002) e Lima et al. (2005), não há horário definido para a abertura das flores, sendo estas inodoras, embora muitos botões florais abram, principalmente, no período da manhã. A antese se caracteriza pelo afastamento lento dos lobos da corola (ca. duas horas). Durante este período, as anteras estão fechadas, mas o estigma está receptivo, caracterizando a fase feminina da flor. Duas a quatro horas após o início da antese as anteras estão abertas, caracterizando a fase hermafrodita. No final do segundo dia, as anteras geralmente estão amareladas e sem pólen e os lobos do estigma não estão mais expostos (Lima et al., 2005; Silva e Bonadeu, 2019).

Na figura 1, está apresentando um indivíduo de $R$. brevifolia em período de floração na área de estudo.

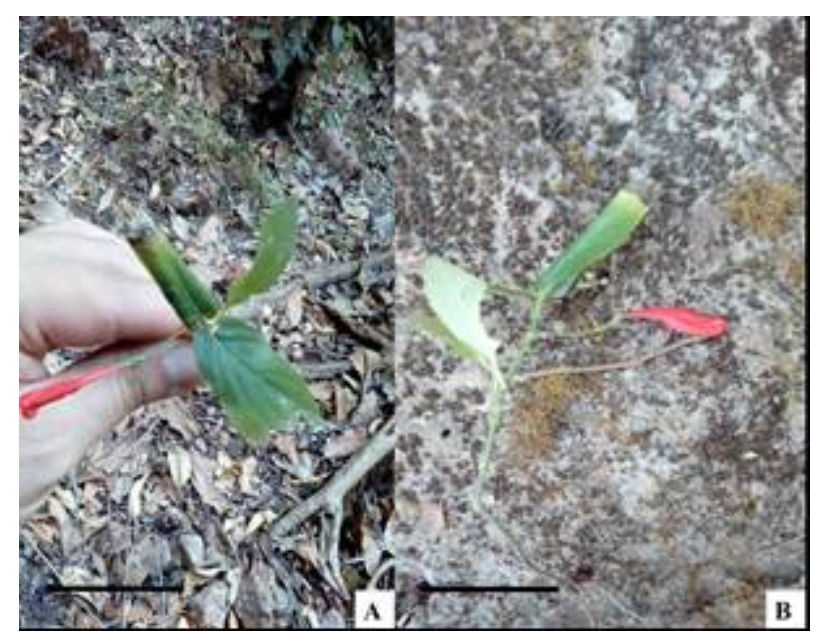

Figura 1 - Registro de Ruellia brevifolia em ambiente natural de vegetação de Mata Ripária (A) serrapilheira e em (B) sobre maciços carlcários. Barras: $30 \mathrm{~cm}$.

O ambiente para este estudo, como descrito anteriormente, apresenta densa área de vegetação Ripária próxima a um curso d'água, o maior adensamento de plantas foi observado na clareira próximo a paredões rochosos de calcário dolomítico onde está localizado uma cachoeira com acesso livre apresentando umidade constante.
Nos estudos de Lima et al. (2005) e Lima e Vieira (2006), os pesquisadores descreveram o ambiente de $R$. brevifolia coletadas no estado de Minas Gerais, Brasil como sub-bosque de floresta, em locais sombreados a parcialmente sombreados com floração e frutificação o ano todo. Sigrist e Sazima (2002) avaliaram grupamentos de $R$. brevifolia em 
locais sombreados de borda de mata semidecídua na Reserva Municipal de Santa Genebra, Campinas, estado de São Paulo, Brasil. Já Ezcurra (1989) descreve sobre o hábito de $R$. brevifolia sendo amplamente encontrada em áreas abertas de mata sujeitas a alterações, como clareiras e beiras de trilhas, bem como encontradas em áreas sombreadas.

Estudos florísticos e taxonômicos realizados no estado de Minas Gerais, Brasil, sobre as Acanthaceae restringem-se a uma listagem de coletas realizadas em diversos municípios (Rizzini, 1949) e ao levantamento de Acanthaceae registradas na Serra do Cipó (Kameyama, 1995), onde predomina vegetação de Campo Rupestre.

Neste estudo foi observado altura de plantas entre 30,5 a $92,8 \mathrm{~cm}$ de altura com $\pm 1,49$ de desvio padrão. Este resultado, corrobora com os demais trabalhos sobre altura de plantas de $R$. brevifolia. No entanto, no estudo de Sigrist e Sazima (2002), os pesquisadores observaram indivíduos com até 2 $\mathrm{m}$ de altura. Alguns indivíduos apresentaram hábito de desenvolvimento sobre rochas de origem calcária, onde suas raízes estavam totalmente descobertas e sem proteção sob material orgânico advindos da serrapilheira.

\section{CONCLUSÕES}

Ruellia brevifolia não apresentou todos os padrões fenológicos observados e descritos em outros estudos em diferentes regiões do Brasil, como período de floração apenas nos meses da estação chuvosa, sendo esta, descontínua não mantendo alternância entre Casmógamas e Cleistógamas e formas intermediárias entre esses dois tipos florais, ou seja, flores CA reduzidas e semicleistógamas, portanto não há formação de sementes durante todo o ano como observado. Outras caracteríscas da espécie discutida foi a presença de indivíduos adultos de $R$. brevifolia se desenvolvendo sobre rochas calcárias apenas com uma fina camada de matéria orgânica promovida pela serrapilheira, e da baixa estatura populacional. Novos estudos de fenologia da floração, bem como dos polinizadores e da caracterização fitoquímica desta espécie de Ruellia deve ser realizado nesta área de estudo.

\section{AGRADECIMENTOS}

Ao Instituto Federal de Educação, Ciência e Tecnologia Goiano, Campus Rio Verde; ao laboratório de Sistemática Vegetal e Herbário.

\section{REFERÊNCIAS BIBLIOGRÁFICAS}

Araújo LLN, Faria MJM, Safadi GMVV. Prospecção fitoquímica da espécie Justicia pectoralis Jacq. var. stenophylla Leonard pertencente à família Acanthaceae. Revista Eletrônica de Ciências Humanas, Saúde e Tecnologia, v.3, n.2, 2014. https://revista.fasem.edu.br/index.php/fasem/article/view/67

Azevedo IHF, Braz DM. Seed morphology of Ruellia L. (Acanthaceae) from the Southeastern Brazilian Atlantic rain forest: Taxonomic, phylogenetic, and ecological aspects. Flora, v.240, p.48-57, 2018. https://doi.org/10.1016/j.flora.2017.12.011

Batalha MA. O Cerrado não é um bioma. Biota Neotropica, v.11, n.1, p.21-24, 2011. https://doi.org/10.1590/S167606032011000100001

Braz DM, Carvalho-Okano RM, Kameyama C. Acanthaceae da Reserva Florestal Mata do Paraíso, Viçosa, Minas Gerais. Revista Brasileira de Botânica, v.25, n.4, p.495-504, 2002. https://doi.org/10.1590/S0100-84042002012000013

Daniel TF. Acanthaceae: Mendoncioideae of Mexico. Acta Botánica Mexicana, v.17, p.53-60, 1992.

Demetrio GR, Curi NHA, Canedo-Júnior EO, Malves K, Faria LB, Coelho FF. Differences in vegetative morphological traits caused by habitat mediates herbivory rates in a perenial herb. Oecologia Australis, v.20, n.4, p.501-508, 2016. http://dx.doi.org/10.4257/oeco.2016.2004.09

Ezcurra C. Ruellia sanguinea (Acanthaceae) y especies relacionadas en Argentina, Uruguay y sur de Brasil. Darwiniana, v.29, n.1/4, p.269-287, 1989.

https://www.jstor.org/stable/23218918

Ezcurra C, Azuke D. Validation and genetic and morphological relationships of Ruellia macrosolen (Acanthaceae) from Southern South America. Systematic Botany, v.14, n.3, p.297-303, 1989. https://doi.org/10.2307/2418920

Ezcurra C. Systematics of Ruellia (Acanthaceae) in southern South America. Annals of the Missouri Botanical Garden, v.80, p.784-845, 1993. https://doi.org/10.2307/2399931

Ferreira RQS, Camargo MO, Teixeira PR, Souza PB, Souza DJ. Diversidade florística do estrato arbustivo - arbóreo de três áreas de Cerrado sensu stricto, Tocantins. Revista Desafios, v.4, n.2, p.69-82, 2017.

https://doi.org/10.20873/uft.2359-3652.2017v4n2p69

Hedrén M, Chase MW, Olmstead RG. Relationships in the Acanthaceae and related families as suggested by cladistic analysis of rbcL nucleotide. Plant Systematics and Evolution, v.194, p.93-109, 1995.

https://doi.org/10.1007/BF00983219

Kameyama C. Acanthaceae. In: Melo MMR, Barros F, Wanderley MGL, Kirizawa M, Jung-Mendaçolli SL, Chiea SAC. (eds.). Flora fanerogâmica da Ilha do Cardoso. São Paulo, Instituto de Botânica, 1991.

Kameyama C. Flora da Serra do Cipó, Minas Gerais: Acanthaceae. Boletim da Universidade São Paulo, v.14, p.1238, 1995.

Kress WJ, Beach JH. Flowering plant reproductive systems. In La Selva - Ecology and natural history of a neotropical rain forest (MacDdade LA, Bawa KS, Hespenheide HA, 
Hartshorn GS. eds.). University of Chicago Press, Chicago, p.161-182, 1994.

Lima NAS, Vieira MF. Fenologia de floração e sistema reprodutivo de três espécies de Ruellia (Acanthaceae) em fragmento florestal de Viçosa, Sudeste brasileiro. Revista Brasileira de Botânica, v.29, n.4, p.681-687, 2006. http://dx.doi.org/10.1590/S0100-84042006000400017

Lima RAF, Gandolfi S. Structure of the herb stratum under different light regimes in the submontane Atlantic Rain Forest. Brazilian Journal of Biology, v.69, n.2, p.289-296, 2009. https://doi.org/10.1590/S1519-69842009000200008

Lima NAS, Vieira MF, Carvalho-Okano RM, Azevedo AA. Cleistogamia em Ruellia menthoides (Nees) Hiern e Ruellia brevifolia (Pohl) C. Ezcurra (Acanthaceae) em fragmento florestal do Sudeste brasileiro. Acta Botanica Brasilica, v.19, n.3, p.443-449, 2005.

https://doi.org/10.1590/S0102-33062005000300004

Long RW. Floral polymorphy and amphimitic breeding systems in Ruellia caroliniensis (Acanthaceae). American Journal of Botany, v.58, n.6, p.525-531, 1971. https://doi.org/10.1002/j.1537-2197.1971.tb10000.x

Long RW. Variation in natural populations of Ruellia caroliniensis (Acanthaceae). Bulletin of the Torrey Botanical Club, v.101, n.1, p.1-6, 1974. https://www.jstor.org/stable/2484813

MacDade LA, Daniel TF, Masta SE, Riley KM. Phylogenetic relationships within the Tribe Justicieae (Acanthaceae): Evidence from molecular sequences, morphology, and cytology. Annals of the Missouri Botanical Garden, v.87, n.4, p.435-458, 2000. https://doi.org/10.2307/2666140

MacDade LA. Breeding systems of Central American Aphelandra (Acanthaceae). American Journal of Botany, v.72, n.10, p.1515-1521, 1985. https://doi.org/10.1002/j.15372197.1985.tb08414.x

MacDade LA, Moody ML. Phylogenetic relationships among Acanthaceae: evidence from noncodigntrnL-trnF chloroplast DNA sequences. American Journal of Botany, v.86, n.1, p.70-80, 1999. https://doi.org/10.2307/2656956

Mendonça RC, Felfili JM, Walter BMT, Silva Júnior MC, Rezende AV, Filgueiras TS, Nogueira PE, Fagg CW. Flora vascular do cerrado: Checklist com 12.356 espécies. In Cerrado: ecologia e flora (Sano SM, Almeida SP, Ribeiro JF, ed.). EMBRAPA-CPAC, Planaltina, p.4171279, 2008.

Miranda AS, Vieira MF. Production of floral morphs in Cleistogamous Ruellia brevifolia (Pohl.) C. Ezcurra (Acanthaceae) at different levels of water availability. Journal of Pollination Ecology, v.19, n.15, p.104-107, 2016. http://dx.doi.org/10.26786/1920-7603\%282016\%298

Newstrom LE, Frankie GW, Baker HG. A new classification for plant phenology based on flowering patterns in lowland tropical forest trees at La Selva, Costa Rica. Biotropica, v.26, n.2, p.141-159, 1994. https://www.jstor.org/stable/2388804

Pedrotti DE, Guarin Neto G. Flora ruderal da cidade de Cuiabá, Mato Grosso, Brasil. Acta Botanica Brasilica, v.12, n.2, p.135-143, 1998. http://dx.doi.org/10.1590/S010233061998000200004
RIZZINI CT. Acanthaceae Minarum generalium impprimis Mello-Barretianae. Arquivos do Jardim Botânico do Rio de Janeiro, v.9, p.193-207, 1949.

Sano EE, Rosa R, Brito JLS, Ferreira LG. Mapeamento de cobertura vegetal do bioma Cerrado: estratégias e resultados. Embrapa Cerrado. Planaltina DF. 2007.

Scotland RW, Sweere JA, Reeves PA, Olmstead RG. Higherlevel systematics of Acanthaceae determined by chloroplast DNA sequences. American Journal of Botany, v.82, n.2, p.266-275, 1995. https://doi.org/10.1002/j.15372197.1995.tb11494.x

Schwarzbach AE, MacDade LA. Phylogenetic relationships of the mangrove family Avicenniaceae based on chloroplast and nuclear ribosomal DNA sequences. Systematic Botany, v.27, n.1, p.84-98, 2002. https://doi.org/10.1043/0363-6445-27.1.84

Sigrist MR, Sazima M. Ruellia brevifolia (Pohl) Ezcurra (Acanthaceae) fenologia da floração, biologia da polinização e reprodução. Brazilian Journal of Botany, v.25, n.1, 2002. https://doi.org/10.1590/S0100-84042002000100006

Silva FA, Bonadeu F. Acanthaceae em Colorado do Oeste, Rondônia, Brasil. Rodriguésia, v.70, e00212018, 2019. http://dx.doi.org/10.1590/2175-7860201970082

Villanueva-Espinoza RM, Condo FM. Sinopsis de la familia Acanthaceae en el Perú. Revista Florestal del Perú, v.34, n.1, p.21-40, 2019. http://dx.doi.org/10.21704/rfp.v34i1.1282

Wasshausen DC, Smith LB. Acantáceas. In: Reitz R, (ed.). Flora ilustrada Catarinense. Santa Catarina, Herbário Barbosa Rodrigues, 1969. 